\title{
DA SOCIEDADE ANÔNIMA À MICRO E PEQUENA EMPRESA: O USO DA TEORIA DA AGÊNCIA PARA SOLUÇÃO DE CONFLITOS
}

Elvis Magno Silva ${ }^{1}$

Antonio Carlos Santos ${ }^{1}$

Olívia Carolina De Resende Ribeiro²

\footnotetext{
${ }^{1}$ Universidade Federal de Lavras

${ }^{2}$ Pós-graduação em Administração / Universidade / UNIVERSIDADE POSITIVO
} 


\title{
DA SOCIEDADE ANÔNIMA À MICRO E PEQUENA EMPRESA: O USO DA TEORIA DA AGÊNCIA PARA SOLUÇÃO DE CONFLITOS
}

\begin{abstract}
Resumo: O problema da agência, segundo Panda e Leepsa (2017), é um dos mais antigos que vem se perpetuando desde a evolução das empresas Sociedade Anônima. Mesmo sendo um problema antigo, é também atual o qual vem ganhando forças ao longo da história do desenvolvimento das trocas comerciais e evolução da constituição de capital das organizações. Mas como podemos utilizar uma teoria idealizada sob pilares das Sociedades Anônimas e aplica-la no contexto das micro e pequenas empresas? Diante desta questão, este trabalho teve como objetivo fazer uma revisão sobre a evolução da Teoria da Agência e mostrar, por meio de um estudo empírico em uma microempresa, como pesquisadores podem usar esta teoria em uma micro e pequena empresa. Este trabalho caracteriza-se metodologicamente como qualitativo e descritivo. Foram utilizados como procedimentos de coleta de dados a entrevista semiestruturada e observação. Concluímos também que as ideias teóricas de conflitos e solução de conflitos provenientes da Teoria da Agência podem vir a ser novas formas de se entender as micro e pequenas empresas.
\end{abstract}

Palavras-chave: Teoria da Agência. Micro e Pequenas Empresas. Solução Conflito.

\section{$1 \quad$ Introdução}

O problema da agência, segundo Panda e Leepsa (2017), é um dos mais antigos que vem se perpetuando desde a evolução das empresas S/A (Sociedade Anônima - empresas de capital aberto). Mesmo sendo um problema antigo, é também atual o qual vem ganhando forças ao longo da história do desenvolvimento das trocas comerciais e evolução da constituição de capital das organizações (WRIGHT, MUKHERJI e KROLL, 2001; e BENDICKSON et al, 2016).

É um problema que não pode ser ignorado, pois todas as organizações possivelmente sofreram e ainda sofrem deste mal de diferentes formas, não somente as S/A mas também micro e pequenas empresas. Com a mudança do tempo, o problema da agência tomou diferentes formas e a literatura tem evidências sobre isso. A análise da literatura sobre teoria da agência é necessária para entender o problema, suas várias formas e os vários custos envolvidos para minimizá-los.

Eisenhardt (1989) explica que a Teoria da Agência está preocupada em resolver dois problemas que podem ocorrer nos relacionamentos.

i. O primeiro é o problema de agência que surge quando: (a) os desejos ou objetivos do principal e do agente conflitam e (b) é difícil ou caro, para o principal, verificar o que o agente está realmente fazendo. O problema aqui é que o principal não pode verificar se o agente se comportou adequadamente.

ii. O segundo é o problema do compartilhamento de riscos que surge quando o principal e o agente têm atitudes diferentes em relação ao risco. O problema neste caso é que o principal e o agente podem preferir ações diferentes por causa das diferentes preferências de risco. 
Tais problemas não são exclusividades das Sociedades Anônimas, eles também podem ser percebidos em micro e pequenas empresas. Assim, como podemos utilizar uma teoria idealizada sob pilares das Sociedades Anônimas e aplica-la no contexto das micro e pequenas?

Diante desta questão, este trabalho tem como objetivo fazer uma revisão sobre a evolução da teoria e mostrar, por meio de um estudo empírico, como pesquisadores organizacionais podem usar esta teoria (originalmente pensada sob os aspectos de uma Sociedade Anônima) em uma micro e pequena empresa. Assim sendo, o trabalho foi estruturado buscando responder quatro questões relevantes. A primeira é sobre "o que é a teoria da agência?" A segunda trata de, "quais os problemas de agência as organizações estão sujeitas?". A terceira verifica "como os conflitos de agência podem ser solucionados?" E por fim, "como pesquisadores podem fazer uso desta teoria no entendimento e busca de soluções para resolução de conflitos organizacionais?"

A busca de respostas para as questões levantadas se deu por meio de levantamento teórico baseado nos artigos mais relevantes sobre teoria da agência na base de dados Scopus (e artigos citados por estes trabalhos mais relevantes) e realização de um estudo empírico em um alambique de produção de cachaça artesanal que se localiza no interior do Estado de Minas Gerais.

Em termos metodológicos, o estudo empírico foi de caráter qualitativo e descritivo, realizado em um Alambique situado em uma fazenda que faz desde o plantio da cana-de-açúcar até a comercialização da cachaça. Foram realizadas duas visitas formais previamente agendadas, nas quais foram utilizados os procedimentos de entrevista e observação para levantamento dos dados. A primeira visita foi feita com o gerente de produção que apresentou os funcionários da empresa, mostrou as atividades dos mesmos e mostrou a fazenda, o local de plantio e produção da bebida. Terminou a visita na loja que é conjugada com a adega de envelhecimento. Após esta visita e conversa informal, iniciou-se a entrevista formal seguindo um roteiro previamente estabelecido que englobava: história da empresa, contexto sócio histórico, estratégia, práticas de produção, práticas mercadológicas e práticas de gestão.

Cerca de 15 dias depois, retornou-se à fazenda para a entrevista com o proprietário. Após uma breve conversa, iniciou-se a entrevista formal seguindo o mesmo roteiro que foi aplicado com gerente de produção. Após a entrevista, o proprietário apresentou o processo produtivo em uma visita guiada. A conversas sobre o negócio da cachaça, suas aspirações e experiências, continuou em um restaurante nas proximidades.

Além destas visitas in loco, visitou-se, no Youtube, duas entrevistas de programas de televisão no alambique em estudo que trouxeram informações complementares. Também coletaram-se informações do site oficial da empresa e a loja virtual.

O Que Diz o Marco Teórico?

\subsection{Evolução}

A apreciação da Teoria da Agência precede sua formalidade advinda de Jensen e Meckling (1976). Ela remonta a um tempo mais antigo, tempo da constituição das Cidadesestados e do final do feudalismo, com o surgimento da classe burguesa; indo a divisão do trabalho promovida pela revolução industrial e pela delegação de tarefas de investimento aos agentes especializados no mercado de ações (LINDER e FOSS, 2015). 
Adam Smith (1996 [1776]) em sua obra A Riqueza das Nações (An Inquiry into the Nature and Causes of the Wealth of Nations - título original), expõe algumas questões ligadas ao problema da agência. $\mathrm{Na}$ ocasião, (p. 392-393), o autor relata a terceirização da administração econômica do feudo. Passando a administração do feudo do soberano para o burgo, que deveria gerenciar toda produção econômica do seu reinado. Em alguns feudos onde o soberano era mais liberal, deu-se margem para os burgos administrarem a seu próprio favor por intermédio de articulações políticas.

Apesar de Adam Smith não concentrar seus esforços neste conflito de interesses (conflito de agências), mas sim em um estudo econômico da época, pode ser percebido a essência da Teoria da Agência, que é o conflito originário da separação do direito de propriedade, onde o proprietário do recurso terceiriza sua utilização com a finalidade de ganhos econômicofinanceiros (RASHID, 2015).

Em 1932, Berle e Mean fomentaram essa preocupação do conflito de agência em sua tese, onde analisaram a estrutura de propriedade das grandes empresas dos EUA e obtiveram que os proprietários nomearam agentes para controlar as grandes empresas e realizar as operações comerciais. Eles argumentaram que os agentes nomeados poderiam usar a propriedade da firma para seu próprio fim, o que criaria o conflito entre os diretores e os agentes (BERLE e MEAN, 1932).

Mas foi nas décadas de 1960 e 1970 que a literatura financeira descreveu o problema de agência nas organizações por meio do problema de compartilhamento de risco entre as partes cooperantes, como pode ser apreciado nos trabalhos de Arrow (1971) - Essays in the theory of risk bearing e Wilson (1968) - On the theory of syndicates. Segundo estes trabalhos, existem indivíduos e grupos com diferentes tolerâncias ao risco dentro da empresa e suas ações diferem de acordo com esta disposição ou não de assumir risco.

O principal ou os proprietários, que investem seu capital e assumem o risco de adquirir os benefícios econômicos, enquanto os agentes, que administram a empresa, são avessos ao risco e preocupados em maximizar seus benefícios privados. Tanto o principal quanto o agente estão tendo preferências de risco opostas e seu problema no compartilhamento de risco cria o conflito de agência, que é amplamente coberto pela teoria da agência.

A confirmação destes apontamentos pode ser verificada também no trabalho de Jensen e Meckling (1976) que comentam que o administrador pode tomar decisões para favorecer a si mesmo ao invés do investidor, pois os administradores de grandes empresas de capital aberto parecem não ser inclinados ao risco se comparados com os detentores do capital próprio. Este fato se vê principalmente em empresas de prestação de serviço público, segundo os autores. A lógica parece ser contrária, o administrador procura evitar riscos ao invés de procurar os maiores ganhos.

Este problema entre o principal e o agente foi estudado por Ross (1973) e Mitnick (1975). Os autores divergem no tocante a causa deste problema. Para Ross (1973), a causa deste conflito de agência entre o principal e o agente se dá devido a questão de incentivos, ou a falta destes. Neste sentido, a causa do problema para Ross (1973) é em consequência da decisão de compensação. Se o agente é bem recompensado pelo principal e se sente satisfeito e valorizado, o mesmo irá agir no interesse deste principal.

Entretanto, para Mitnick (1975) a causa deste conflito entre principal e o agente, é um problema da estrutura institucional. O oportunismo do agente se dá mediante uma brecha ou lacuna nas normas e regras que regem o contrato ou o mercado no qual se está atuando. Foi esta abordagem institucional de Mitnick que ajudou a desenvolver as lógicas da teoria central da 
agência e possivelmente foi concebida para entender o comportamento do mundo real. Sua teoria propagou que as instituições são construídas em torno da agência e se evoluem (ou adaptam) para se reconciliar com a agência.

Jensen e Meckling (1976) retrataram a empresa como uma caixa preta, que opera para maximizar seu valor e rentabilidade. A maximização da riqueza pode ser alcançada através de uma coordenação adequada e trabalho em equipe entre as partes envolvidas na empresa. No entanto, o interesse das partes difere, o conflito de interesses então surge e só pode ser remediado por meio de controle e ação gerencial. As partes interessadas (principal e agente) também devem possuir consciência de que seu interesse só pode ser satisfeito se a empresa existir. Assim, eles devem garantir o bom funcionamento para a sobrevivência da empresa.

Da mesma forma, Fama (1980) defendeu que as firmas podem ser disciplinadas pela competição dos demais jogadores, que monitora o desempenho de toda a equipe e das pessoas individualmente.

Mas foi no final da década de 1980 que Eisenhardt (1989) classificou a teoria da agência em dois modelos, o modelo de agência positivista e o modelo de principal. Os dois modelos compartilham uma unidade comum de análise: o contrato entre o principal e o agente. Eles também compartilham suposições comuns sobre pessoas, organizações e informações. No entanto, eles diferem em seu rigor matemático, variável dependente e estilo. Pode-se dizer segundo a autora, que o modelo principal-agente é mais matemático do que o modelo positivista.

O foco da literatura sobre o agente principal está na determinação do contrato ótimo, comportamento versus resultado, entre o principal e o agente. $\mathrm{O}$ modelo simples pressupõe conflito objetivo entre o principal e o agente, um resultado facilmente mensurável e um agente que é mais avesso ao risco do que o principal (EISENHARDT, 1989).

Já o modelo positivista concentrara-se em identificar situações nas quais o principal e o agente provavelmente têm objetivos conflitantes e, em seguida, descrevem os mecanismos de governança que limitam o comportamento de autosserviço do agente. O modelo positivista é menos matemático. Além disso, os pesquisadores positivistas concentram-se quase exclusivamente no caso especial da relação principal-agente entre proprietários e administradores de grandes corporações públicas. De uma perspectiva teórica, a corrente positivista tem estado mais preocupada em descrever os mecanismos de governança que resolvem o problema da agência (EISENHARDT, 1989).

\subsubsection{Tipos de problemas de agência}

Segundo Panda e Leepsa (2017) os tipos de problemas de agência podem ser classificados em três categorias: Tipo 1, problema entre principal e o agente; Tipo 2, problema do principal majoritário com o principal minoritário; Tipo 3, problema do principal com o credor.

\section{Tipo 1 - problema entre principal e o agente}

O problema da agência entre proprietários e gerentes nas organizações, se dá devido à separação da propriedade do controle. Ou seja, quem detém a propriedade não é o mesmo que a controla. Os proprietários atribuem a tarefa aos gerentes para administrar a empresa com a esperança de que os gerentes trabalhem em benefício dos proprietários. No entanto, os gerentes estão mais interessados na maximização de sua própria remuneração. $\mathrm{O}$ argumento sobre o comportamento auto satisfatório do agente é baseado na racionalidade do comportamento 
humano, que afirma que as ações humanas são racionais e motivadas para maximizar seus próprios fins. $\mathrm{O}$ desalinhamento de interesses entre o principal e o agente e a falta de monitoramento adequado devido à estrutura de propriedade difusa leva ao conflito, que é conhecido como conflito entre o principal e o agente (PANDA e LEEPSA, 2017; WISEMAN, RODRÍGUEZ e MEJIA, 2012).

\section{Tipo 2 - problema do principal majoritário com o principal minoritário}

A suposição subjacente desse tipo de problema de agência é o conflito de interesses entre os proprietários majoritário e minoritários. Os principais proprietários majoritários são denominados como uma pessoa ou grupo de pessoas que detêm a maioria das ações de uma empresa, enquanto os proprietários minoritários são aqueles que detêm uma parte muito menor da participação da empresa. Os proprietários majoritários ou bloqueadores têm maior poder de voto e podem tomar qualquer decisão a favor de seu benefício, o que dificulta os interesses dos acionistas minoritários. Esse tipo de problema de agência prevalece em um país ou empresa, onde a propriedade está concentrada nas mãos de poucas pessoas ou com os proprietários da família, então os acionistas minoritários acham difícil proteger seus interesses ou riqueza (PANDA e LEEPSA, 2017).

\section{Tipo 3 - problema do principal com o credor}

$\mathrm{O}$ conflito entre os proprietários e os credores surge devido aos projetos realizados e à decisão de financiamento tomada pelos acionistas (DAMODARAN, 1997). Os acionistas tentam investir nos projetos arriscados, onde esperam maior retorno. $\mathrm{O}$ risco envolvido nos projetos aumenta o custo do financiamento e diminui o valor da dívida pendente, que afeta os credores. Se o projeto for bem-sucedido, então os proprietários irão desfrutar dos enormes lucros, enquanto o interesse dos credores é limitado, pois eles recebem apenas uma taxa fixa de juros. Por outro lado, se o projeto falhar, os credores serão obrigados a compartilhar algumas das perdas e, geralmente, esse problema persiste nesses tipos de circunstâncias (PANDA e LEEPSA, 2017).

\subsubsection{Solucionando o problema da agência}

A apreciação acima mostrou que, independentemente dos níveis de assimetria de informação entre o principal e o agente, ainda existe o potencial de incorrer custos de agência devido ao comportamento oportunista do agente. $\mathrm{O}$ foco da teoria da agência é determinar $\mathrm{o}$ contrato mais eficiente que rege o relacionamento entre o principal e o agente, dadas as suposições sobre pessoas (por exemplo, interesse próprio, racionalidade limitada, aversão ao risco), organizações (por exemplo, conflito de objetivos entre membros) e informações (por exemplo, a informação é uma mercadoria que pode ser comprada) (MASON e SLACK, 2005).

Eisenhardt (1989) em uma revisão da literatura da agência, identificou duas maneiras pelas quais os teóricos da agência argumentam que os princípios podem parar esse comportamento indesejado:

$\checkmark$ Solução 1, criar mecanismos de monitoramento; e

$\checkmark$ Solução 2, contrato baseado no resultado do agente. 


\section{Solução 1 - criar mecanismos de monitoramento}

Os mecanismos de monitoramento são úteis em situações em que o desempenho do agente pode ser facilmente avaliado. A lógica aqui é que, como o agente tem menos probabilidade de agir furtivamente se estiver sendo monitorado, o comportamento oportunista será reduzido. No entanto, os custos de monitoramento são apropriados apenas quando os custos incorridos para reduzir o descuido não excedem o valor dos recursos consumidos pelo agente que está se esquivando. Em outras palavras, os custos de monitoramento não devem exceder as potenciais perdas residuais da ação oportunista (MASON e SLACK, 2005).

Por exemplo, não seria viável instalar um sistema de vigilância por vídeo em um alambique que produz cachaça para detectar o roubo de cana de açúcar por parte de um funcionário se o sistema de vigilância custar mais à empresa do que a cana que é roubada. No entanto, há casos em que a criação de mecanismos de monitoramento afeta o relacionamento entre principal-agente, pois pode-se questionar a honestidade do agente fazendo com que este colaborador se sinta insatisfeito no serviço, ou ao contrário, o monitoramento pode proporcionar maior simetria de informações entre principal e agente melhorando o desempenho das tarefas.

Mason e Slack (2001) ainda comentam que o monitoramento do comportamento do agente não é necessariamente de responsabilidade exclusiva do diretor. Em alguns casos, os governos estaduais se envolverão na regulamentação do comportamento dos agentes ou nas associações profissionais dentro do campo dado pelo agente.

\section{Solução 2, contrato baseado no resultado do agente}

Embora o aumento das informações disponíveis para o principal em relação ao comportamento do agente possa reduzir os custos de agência, a solução mais comumente discutida para os problemas de agência requer contratar baseado no resultado do comportamento do agente. A lógica por trás dessa prática é que, se o objetivo do principal é a maximização do lucro, a solução para os problemas é dar ao agente uma recompensa que esteja atrelada ao desempenho financeiro da própria empresa (MASON e SLACK, 2005).

No entanto, ao criar um contrato baseado em desempenho, pode ocorrer uma transferência de risco do principal para o agente. Isso acontece porque os agentes tomam decisões benéficas que podem afetar toda a organização, mas são recompensados apenas com uma parte dos resultados (uma comissão). Em contraste, um agente que toma decisões erradas ou apresentam um desempenho insatisfatório, pode não receber uma recompensa (se usar um sistema de pagamento baseado somente em desempenho). Por essa razão, os agentes podem ser encorajados a agir de modo a assegurar um nível mínimo de recompensa, em vez de buscar oportunidades que possam ser do melhor interesse da organização. Portanto, se o agente tiver aversão ao risco; ele escolherá oportunidades de investimento que reduzirão o risco (MASON e SLACK, 2005).

Assim, a solução para os problemas seria adotar um pagamento base fixo e ao mesmo tempo uma comissão atrelada ao desempenho. Este desempenho poria ser diretamente atrelado ao ganho econômico ou financeiro da empresa ou não. Por exemplo, um vendedor de seguros de uma financeira poderia ter um salário fixo e um bônus atrelado ao valor monetário da venda de seguros, ou ter um salário fixo e ter um bônus atrelado a quantidade de pessoas atendidas ou visitadas, ou ainda ter um salário fixo e ter um bônus atrelado ao nível de satisfação dos clientes que contrataram o seguro (mediante a aplicação de uma pesquisa de satisfação do cliente). Estes são apenas alguns exemplos que poderiam ser seguidos no intuito de resolver este conflito de agência. 
Cabe explicar que o termo risco não deve ser confundido com a incerteza, que pressupõe a imprevisibilidade do futuro, mas pelo contrário, o risco diz respeito ao nível de retorno competitivo que será exigido por um portador de risco para um certo grau de risco que é assumido (JONES e BUTLER, 1992).

Jones e Butler (1992) ainda comentam que a teoria da agência sustenta que ao dar ao gerente uma recompensa financeira, ou oferecer bônus com base no desempenho da organização (quaisquer que sejam os interesses do proprietário), o gestor terá um incentivo maior para aumentar a riqueza da empresa, pois isso acabará por aumentar a sua própria riqueza pessoal. No entanto, os agentes ainda terão aversão ao risco, pois só serão recompensados por uma atividade empreendedora bem-sucedida.

Usando um exemplo de esporte profissional, Mason e Slack (2005) expõe que os atletas profissionais que são menos avessos ao risco estão mais dispostos a aceitar contratos com incentivos baseados no desempenho da equipe ou pessoal. Esses atletas receberão mais por serem bem-sucedidos porque receberão um prêmio de risco por aceitar um contrato sem garantias.

\subsection{O Que Mostra o Estudo Empírico?}

\subsubsection{Caracterização do objeto de estudo}

Localizada no interior do Estado de Minas Gerais (Brasil), o Alambique Mineiro é uma microempresa privada cujos sócios são um casal de aposentados, doravante principais, os quais constituíram esta sociedade de capital de baixa tecnologia, mas com uma alta especificidade de ativo.

Os principais, oriundos da região Sul do Brasil, após aposentarem-se participaram de um curso de "Mestre Alambiqueiro" na cidade de Belo Horizonte capital do Estado de Minas Gerais. Encantados com o curso decidiram abrir um alambique para produção de cachaça artesanal. Como já conheciam o interior de Minas Gerais, e na busca de uma nova experiência para esta etapa de suas vidas, os principais fizeram a aquisição de uma fazenda para montagem de um alambique para produção de cachaça artesanal.

O objetivo inicial deste novo empreendimento não era a lucratividade, mas sim ter uma ocupação prazerosa em meio a natureza e a possibilidade de conhecer outras pessoas por intermédio deste novo negócio. Contudo, como mencionado pelo proprietário na entrevista in loco, "não há nada de errado em se ganhar algum dinheiro fazendo o que se gosta". Neste caso, além do ganho de bem-estar, associa-se a este, o ganho econômico e o ganho social.

A forma de conduzir o negócio é bem particular do proprietário, o mesmo durante sua carreira profissional trabalhou em empresas que zelaram muito pela qualidade e honestidade. Assim sendo, a condução do alambique se dá da mesma maneira, com um zelo pela qualidade em todos os processos produtivos, bem como pela honestidade ao lidar com os colaboradores e clientes.

O alambique conta com a direção geral de seu principal majoritário, o proprietário, conta também com dois gerentes, sendo um administrativo e outro de produção, e mais quatro colaboradores fixos e dois temporários. O relacionamento do proprietário com os gerentes é bem aberto, cuidando em manter um bom relacionamento. A gerente administrativa, é filha dos principais e cuida da parte de compra, vendas, atendimento ao cliente, site, contas a pagar entre outras funções administrativas. O gerente de produção, também aposentado (professor), cuida 
da produção da cachaça, supervisionando os colaboradores e atuando ativamente no processo de conversão do caldo da cana em álcool e na extração das impurezas no alambique.

A fazenda onde foi montada o alambique possui plantação de cana de açúcar de uma espécie específica para produção de cachaça. Conta também com dois alambiques e uma adega com barris de madeira para o envelhecimento da bebida. Ao todo são 6 tipos de madeiras diferentes para envelhecimento, o que torna o ativo mais específico e com um valor agregado. Atualmente a cachaça mais valorizada da empresa é a envelhecida de dois anos em barril de carvalho americano. O proprietário ainda aguarda a maturação de outra cachaça que é, segundo o mesmo, "a menina dos olhos", que é uma cachaça que está sendo envelhecida em barril de carvalho europeu que já foi utilizado para envelhecer Vinho do Porto o qual foi adquirido de uma vinícola portuguesa após seu uso.

\subsubsection{Práticas mercadológicas e de gestão segundo o ponto de vista do gerente de produção}

Durante a entrevista com o gerente de produção, este relatou que o mais importante canal de vendas da empresa é o online. Isto porque a empresa ainda é nova no mercado (cerca de 3 anos) e conta apenas com uma loja que está dentro da mesma fazenda onde fica o alambique. Entretanto, o número de vendas na loja do alambique vem aumentando. $\mathrm{O}$ gerente atribui este aumento devido estar localizado em uma região turística e conjuntamente com uma visita guiada que leva o cliente desde o local de extração da cana até a adega de armazenamento onde ficam os barris de envelhecimento.

Cabe ressaltar que a loja da fazenda fica junto com a adega de envelhecimento e que a mesma possui uma cafeteria e uma mesa de degustação das cachaças do alambique. $\mathrm{O}$ ambiente é confortável e com requinte. Da entrada da fazenda até a loja há um trabalho de paisagismo que torna o local mais aprazível.

$\mathrm{Na}$ loja, além da possibilidade de comprar o produto principal (cachaça) o cliente pode adquirir doces típicos (feito por terceiros) e souvenirs como chaveiros, canecas e minigarrafas de cachaça. Também pode ser apreciado um café com pão de queijo (tradicionais da região).

O gerente também comenta que as vendas tanto da loja como do site são para clientes do varejo. A empresa não possui uma política para venda no atacado. O gerente comenta que o proprietário não tem nenhuma intensão ou motivação para vender para o atacado, seja para um representante comercial ou um centro de distribuição. E ainda que são poucos os locais comerciais fora da loja da fazenda em que se pode degustar a bebida do alambique mineira. $\mathrm{Na}$ cidade e mediações da fazenda (interior de Minas Gerais) a bebida pode ser encontrada em apenas dois restaurantes, os quais são reconhecidos nacionalmente, um pela sua culinária e outro pelo seu requinte. E na região Sul do Brasil, em outros dois restaurantes também reconhecidos pelo requinte.

O gerente comenta que esta é uma estratégia do proprietário, de querer posicionar seu produto, vinculando sua bebida a restaurantes renomados e frequentado por uma clientela com maior poder aquisitivo e que esteja acostumado com bebidas mais sofisticadas e que saibam valorizar este tipo de bebida. Não é desejo do proprietário que sua bebida seja vinculada a "beberrões" ou popularizada de forma a ser encontrada em qualquer bar.

Contudo, o gerente acredita que o proprietário poderia abrir mais seu leque de vendas sem perder este posicionamento. Por exemplo, a loja já foi visitada por um revendedor que trabalha com restaurantes na cidade do Rio de Janeiro e que o mesmo pediu um preço menor (desconto na compra) para poder inserir a bebida em restaurantes de Copacabana, Botafogo e mediações.

DOI: 10.14211/xi-egepe-117996 
Porém o proprietário não quis baixar o preço nem chegar a um acordo com este revendedor. "Caso fizesse um desconto, poderia ter ganho em escala na quantidade que seria vendida para o revendedor", disse o gerente.

Perguntado ao gerente se já participaram em feiras e eventos levando sua cachaça para concorrer a prêmios ou somente para expor, o gerente respondeu que não. Apesar de acreditar que seria bom para marca, para se tornar mais conhecida entre os apreciadores e "apaixonados" pela bebida que frequentam estas feiras e eventos.

Ainda conversando sobre o negócio da empresa, o gerente relatou que trabalha para o principal desde do início das construções na fazenda para torna-la um alambique. E que em todo este período trabalhando na empresa presenciou somente uma desinteligência de um funcionário com o proprietário. Comentou que esta desinteligência se deu no primeiro ano do alambique, quando ao lado da loja da fazenda havia uma pequena lanchonete para venda de caldo de cana (garapa) e pastel.

O proprietário, por ser vegetariano, não permitia a venda de pastel recheado com alimentos cárneos, somente a base de queijo. A funcionária descordava sempre do proprietário dizendo que o mesmo estava perdendo a oportunidade de ganhar dinheiro com a venda de pasteis com recheio cárneo, pois eram os mais procurados pelos clientes. O gerente de produção apesar de concordar com a funcionária, comentou que "este é o brinquedo dele e ele nos convidou para brincar com ele, só que temos que brincar do jeito que ele quer", se referindo ao proprietário (ele) e a seu negócio (brinquedo).

Como a funcionária ficava sempre irritada com tal situação e inconformada com o proprietário em não querer fazer os desejos dos clientes (pastel de carne), a mesma sempre entrava em desinteligência com o proprietário até que este resolveu fechar a pequena lanchonete e demitir a funcionária.

\subsubsection{Práticas mercadológicas e de gestão segundo o ponto de vista do proprietário}

O principal majoritário, proprietário da empresa, comentou que está muito feliz porque o negócio está começando a se auto sustentar. Que as vendas da loja física já são o suficiente para pagar os funcionários e as despesas mensais. Comentou que não tem a pretensão de ganhar muito dinheiro com o negócio, mas também não quer que este dê prejuízo. Conseguindo se manter, já é o suficiente para ele.

$\mathrm{O}$ proprietário explicou que quando decidiu abrir o negócio junto com sua esposa (principal minoritária), pensou muito na questão da venda do produto, pois não queria ser apenas mais uma cachaça "comum", barata, sendo vendida nos bares. Pois se fosse deste jeito, ele teria que ter uma alta produção para poder pagar seus custos, já que a cachaça "comum" é muito barata, chegando a ser vendida de US\$ 1,00 a US\$3,00 dólares o litro.

Logo, decidiu produzir uma cachaça com uma maior especificidade, com maior valor agregado, de forma a não ter que desprender todo seu tempo e esforço na produção. Produzir uma bebida que pudesse ser vendida a US\$ 30,00, US\$ 40,00 ou até US\$ 50,00 dólares o litro. Desta forma teria uma produção menor, com menos esforço de trabalho, com um ganho capaz de sustentar o empreendimento e que ainda sobrasse tempo para poder viajar com a esposa e aproveitar a aposentadoria (que é o desejo da principal minoritária).

Perguntado sobre planos futuros para o negócio, sobre expansão, o proprietário respondeu que tem dois projetos em mente e um terceiro se o filho dele quiser. O primeiro projeto é um bar no centro turístico da cidade onde está localizado o alambique. Mas não seria um bar

DOI: 10.14211/xi-egepe-117996 
convencional. Seria um bar especializado, com bebidas requintadas, com um ambiente harmonizado e decorado com uma arquitetura tradicional mineira antiga mesclada com um certo requinte e sofisticação que atrairia sua clientela.

O segundo projeto, que está um pouco mais longe, mas que é do agrado da sua esposa (principal minoritária), é a abertura de uma loja para revendas e degustação na Itália (Europa). O mesmo mencionou que já deram (ele e esposa) entrada em toda documentação para ter a cidadania italiana e que a partir de 2019 já seriam cidadãos italianos. De início ele faria a exportação de cachaça do interior de Minas Gerais para a Itália e posteriormente uma pequena adega de envelhecimento lá. Só que para este projeto, ele teria que comprar mais um alambique para aumentar a produção no Brasil para poder exportar para a Itália.

O terceiro projeto que só seria viável caso seu filho resolvesse assumir, era abrir um restaurante na fazenda do alambique, mas especificamente dentro da adega de envelhecimento. Comentou que em sua última viajem à Itália, ele visitou um vinhedo e a visita terminou na adega de envelhecimento e esta era um restaurante. Ressaltou que a experiência foi muito boa e que gostaria de ter um restaurante em seu alambique nestes moldes, contudo não gostaria de assumir mais responsabilidade, mais trabalho, e como seu filho está formando chefe de cozinha e irá a gerencia administrativa do alambique no lugar de sua irmã, pensou que ele poderia assumir a gerencia do restaurante também.

Ainda sobre planos futuros para empresa, perguntamos se já pensou em ter um representante de vendas e prospectar novos mercados além do mercado local e do Sul do Brasil. O proprietário comentou que não tem interesse em vender em grande escala. Que com um representante de vendas, ele teria o compromisso da produção de certa quantia de litros de cachaça e de cumprir prazos, e preocupações com a logística entre outros. "Como já sou aposentado", relatou ele, não quer mais ficar se matando em trabalhar nem em se preocupar em alcançar metas de produção ou prazos de entrega. Disse ainda: "tenho o meu negócio é para mim", se referindo a seu bem-estar e qualidade de vida.

\subsection{Conflitos de Agências}

Iniciando a análise do caso, retomamos o que foi apresentado por Panda e Leepsa (2017) neste artigo, no tocante aos tipos de conflito advindos do problema de agencias. Foi possível identificar dois dos três tipos de problemas, a saber: a do Tipo I, problema entre o principal (proprietário) e o agente (gerente produção); e a do Tipo II, problema entre o principal majoritário (proprietário) e o principal minoritário (esposa do proprietário). Ressaltamos ainda que a do Tipo III não se enquadra no caso, haja visto que todo o investimento feito para aquisição da fazenda, compra de maquinário, obras de construção, contratação de funcionários entre outros, veio de recursos próprios dos sócios, não havendo assim um credor externo, um terceiro.

Também ressaltamos no início desta análise que por se tratar de uma empresa Ltda. e não uma S/A, de início não foi objeto da pesquisa entrevistar a principal minoritária, apesar de ter sido identificado nas entrevistas e conversas com funcionários que os desejos da principal minoritária divergem do principal majoritário. Enquanto a minoritária deseja aproveitar mais a aposentadoria viajando e passando tempo com a família, o majoritário pensa em tocar um negócio comercial no centro da cidade onde se encontra a fazenda, passando assim mais tempo trabalhando do que com a esposa. Tanto, que a minoritária quase não aparece na fazenda- 
alambique ou loja da fazenda, segundo funcionários e gerentes, demonstrando assim falta de interesse pelo empreendimento.

Destaca-se então o problema Tipo I, entre o proprietário e o gerente de produção. Iremos montar um paralelo temático onde ambos entram em assimetria. Após apresentar esta assimetria entre o principal e o agente, será apresentado alguns pontos identificados na pesquisa que buscam solucionar este conflito, e ainda, será feita sugestões de novas práticas para amenizar ainda mais a assimetria com o intuito de alinhar as ações do agente com a do principal. Cabe ressaltar que devido a limitação de páginas para este artigo, vamos concentrar a análise e discussão em apenas três problemas de assimetria: (i) aquisição de mais um alambique; (ii) prospecção em novos mercados nacionais; e (iii) lanchonete com pastel e caldo de cana.

\subsubsection{A aquisição de mais um alambique}

\section{Assimetria}

Dando cabo do paralelo entre o ponto de vista do proprietário e do gerente, destaca-se o desejo do principal em adquirir um terceiro alambique para seu negócio, de forma a aumentar a produção em $50 \%$, pois atualmente o empreendimento já conta com dois alambiques. Este aumento segundo desejo do principal, é para poder exportar a bebida para a Itália. Mas não só exportar o produto engarrafado, pronto para venda, mas sim, ter uma adega de envelhecimento na Itália, de forma a agregar valor ao seu possível novo negócio. Levando a clientela ter a oportunidade de conhecer o local dos barris de envelhecimento, local este que irá proporcionar uma experiência sensorial advinda da especificidade do local, provocando os sentidos, como os odores adocicados das madeiras embebida em cachaça, humidade ambiente, baixa luminosidade e diferente propagação do som.

Para o atual empreendimento, o principal desprenderia apenas um investimento em maquinário e outro investimento em tramites logísticos. Só que para o gerente de produção, isso significa um aumento considerável em sua jornada de trabalho. $\mathrm{O}$ agente explicou que os funcionários operacionais ficam por conta da corte da cana, moenda da cana (extração do caldo), medição de açúcares e filtração, aquecimento da fornalha e limpeza geral. Deste passo em diante as operações são realizadas por ele próprio, o gerente de produção. Ou seja, além de supervisionar as demais atividades, ele participa da produção de forma operacional, cuidando da etapa de fermentação, alambicagem (fervura, extração de impurezas, coleta da cachaça pura), descanso e envelhecimento.

O gerente de produção comentou que não tem mais idade e pique para isso, já é aposentado, e não quer ter que "se matar" trabalhando. Seu trabalho no alambique é para ocupar o tempo, para ajudar um amigo e ter uma renda extra. Ele foi taxativo ao dizer ao proprietário que não trabalharia com um alambique a mais. Em contrapartida, o proprietário comentou que não confia a produção de sua cachaça a mais ninguém, pois apesar de ser permitido por lei um certo nível de impureza, sua tolerância é zero para impurezas, a qualidade de sua bebida deve ser inquestionável.

\section{Solução observada}

Para solucionar a aquisição de mais um alambique, o principal propôs ao gerente de produção que escolhesse uma pessoa de sua confiança para treinar no trabalho operacional que o gerente vinha executando. Desta maneira, o gerente de produção não participaria da produção operando mais os equipamentos, e sim, gerenciando. O agente aceitou a sugestão e escolheu 
um funcionário de sua confiança e passou a treiná-lo na execução das atividades. Durante a visita o gerente ainda era o responsável pela operacionalização de parte da produção, mas explicou que já estava preparando um funcionário para assumir seu posto operacional.

\section{Sugestão}

Como sugestão para o problema do aumento da produção advindo pelo desejo da aquisição de mais um alambique, a proposta é o que já foi apreciado por Mason e Slack (2005) neste artigo, que é a implementação de um bônus de produção ao gerente de produção além do seu atual salário. Como o gerente ainda está assumindo a responsabilidade operacional de parte da produção, apensar de estar treinando um substituto, ele poderia ser mais solícito ao aumento da produção se visse algum ganho monetário neste aumento. Desta forma poderia compartilhar mais favoravelmente do pensamento do proprietário, garantindo uma menor assimetria entre os mesmos.

\subsubsection{Prospecção em novos mercados nacionais}

\section{Assimetria}

O principal foi veemente contra a prospecção em novos mercados nacionais. Mencionou não querer ter que assumir compromisso com grandes vendas, baixando seu preço e ter que lucrar com a venda em escala. Que seu objetivo inicial foi exatamente o contrário, queria lucrar por intermédio de poucos produtos vendidos a um preço mais caro para atender uma clientela de maior poder aquisitivo.

Já o gerente de produção pensa que seria possível ter um represente de vendas sem perder o público alvo do negócio. Como mencionado anteriormente, o representante que visitou a empresa prospectava na região nobre da cidade do Rio de Janeiro (Copacabana entre outros). Perguntado se não seria igual ao aumento para exportação, o mesmo respondeu que não e explicou que no caso da exportação, o proprietário queria adicionar a produção um terceiro alambique, para que o volume da produção aumentasse no período de safra. Já no caso do aumento das vendas nacionais, a produção seria acionada na entressafra, de forma a se produzir em um período que atualmente é ocioso.

\section{Solução observada}

Neste problema o gerente (agente) desejava maior eficiência na produção, aproveitando o período ocioso que ocorre todo ano na entressafra. Com a intensão de amenizar esta insatisfação, o principal (proprietário), propôs uma jornada de trabalho mais flexível ao gerente durante o período de entressafra. Desta forma, o gerente poderia aproveitar melhor seu tempo em outras atividades fora do alambique, do que ficar focado na ociosidade operacional da entressafra.

Ainda no tocante a este último problema, o principal também delegou ao gerente de produção a responsabilidade de executar a visita guiada com os clientes qual ele, o proprietário, não estivesse na fazenda. Desta forma, diminui-se a ociosidade, bem como proporcionou ao gerente de produção ocupar seu tempo no relacionamento com os clientes, atividade esta que o gerente relatou ser uma das mais prazerosas atualmente para ele. 


\section{Sugestão}

Além da flexibilidade na jornada de serviço e da visita guiada, pode-se propor ao principal realizar um monitoramento (ou acompanhamento) da produção, garantindo que esta não esteja produzindo mais do que o necessário. Como foi apreciado, a vontade do gerente de produção é aumentar a produção para ganhar eficiência e ter mais produtos estocados para um futuro aumento das vendas. Neste sentido, havendo um monitoramento, seria garantido que fosse produzido somente o desejado pelo proprietário. E esse monitoramento não seria custoso, pois basta acompanhar a quantidade de cana que está sendo cortada para moenda. Garantindo a quantidade certa de caldo de cana, seria garantido o volume final da produção da cachaça, como proposto pela revisão da literatura de Mason e Slack (2001).

\subsubsection{A lanchonete com pastel e caldo-de-cana}

\section{Assimetria}

Como explicado anteriormente, no início das atividades do alambique, o proprietário abriu uma lanchonete para venda de pastel e caldo de cana, que é uma combinação tradicional no interior de Minas Gerais. Só que devido o proprietário ser vegetariano, este não permitia a venda de pastel com recheio de produtos cárneos. Neste sentido, a opção que ele oferecia para os clientes era somente pastel recheado com queijo. O principal ainda relatou que foi um mau empreendimento a lanchonete, porque dava muito trabalho e pouco retorno. Além de destoar completamente do restante de seu negócio (loja e cafeteria) que eram requintadas e a lanchonete não.

Para o gerente de produção, esta lanchonete era uma ótima opção de negócio. Que poderia ser um diferencial para atrair mais clientes, turistas que passavam pela localidade. Que não custaria nada vender produto de carne, como ele mesmo disse: "ele não come carne, mas tem quem coma" (se referindo ao proprietário). O gerente, antes da flexibilização da jornada de trabalho, chegou a se oferecer para tomar conta da lanchonete, que ele faria com que ela desse certo. Contudo não teve seu pedido atendido. O proprietário havia dito para não perder o foco no negócio principal, e que a lanchonete havia sido um erro.

\section{Solução observada}

A solução realizada pelo proprietário nesta assimetria foi simples, porém extrema. $\mathrm{O}$ proprietário fechou a lanchonete. Durante a visita, pôde ser observado que a construção física da lanchonete está abandonada. E segundo o gerente, todos os materiais ainda estão dentro da mesma. O proprietário disse que ainda pensa em aproveitar o local, mas ainda não sabe ao certo o que irá fazer.

\section{Sugestão}

De fato, nos moldes que se encontrava (em termos de estrutura), a lanchonete não iria ser atrativa para o público alvo desejado pelo principal. Acabaria por atender duas clientelas, uma na loja do alambique (cafeteria) e outra na lanchonete ao lado. Talvez, devido a discrepância entre os públicos que frequentariam cada um dos dois negócios, não fosse de fato viável ter ambos.

Mas neste sentido, e considerando o desejo futuro de abrir um restaurante na adega de envelhecimento, sugere-se demolir a estrutura e criar um paisagismo no local. Pois a visão da lanchonete fechada remete sempre ao gerente que ele poderia estar tocando este 
empreendimento, e com a demolição, com o passar do tempo, este pensamento fícaria no passado, não vívido na mente como quando nos relatou com certo pesar.

\section{Conclusões}

Como a discussão acima sugere, a Teoria da Agência tem muitas possibilidades de aplicações para pesquisas em estudos de micro e pequenas empresas. Como observado no início deste trabalho, a teoria desenvolveu-se a partir da teoria econômica tradicional da empresa, que originalmente analisou a relação entre a administração e a propriedade. A separação entre administração e propriedade gerou o conflito entre este agente administrador e o dono da propriedade o principal.

No tocante a Teoria da Agência, foram feitas duas observações importantes baseadas na apreciação da literatura, a primeira delas é quanto a classificação dos tipos de problemas de agência que podem ser encontrados nas organizações. Neste sentido, foi observado três tipos de conflitos: o conflito entre principal e agente; o conflito entre principal majoritário e principal minoritário, e o conflito entre principal e credor. A segunda observação diz respeito as possíveis soluções para estes conflitos de agência. Foram destacadas duas soluções: a solução por intermédio da criação de mecanismos de monitoramento; e a solução baseada no resultado do agente.

Apesar destas observações, pode ser percebido também que a medida com que as organizações se estruturam e ficam mais complexas, também aumentam as assimetrias de informações entre agentes e principais, surgindo novos conflitos entre agentes e um aumento nos custos de transações advindos de um maior monitoramento ou de melhores planos de incentivo. Tudo isso na tentativa de amenizar as assimetrias advindas da separação do direito de propriedade. Pesquisas futuras podem basear-se na pesquisa empírica existente sobre a teoria da agência, concentrando-se na dicotomia de principal-agente com níveis variados de monitoramento, assimetria de informação, aversão ao risco, oportunismo e funções de utilidade. Esperamos que essa discussão forneça um ponto de partida para novos estudos ao testar as premissas básicas do modelo de agência. Embora o foco da pesquisa da Teoria da Agência tenha sido direcionado para a maximização do lucro financeiro em empresas Sociedade Anônimas, os estudos das micro e pequenas têm demonstrado que é possível a utilização desta teoria com recompensas que vão muito além do ganho financeiro.

Pesquisas adicionais nessa área também podem considerar que a Teoria da Agência é uma teoria útil para os pesquisadores do campo dos estudos organizacionais e gestão de negócios poderem compreender ainda mais as organizações. Haja vista possibilitar a identificação dos tipos de conflito de agência, bem como propor soluções para resolver ou amenizar estes conflitos. Além disso, os termos implícitos dos relacionamentos de agência devem ser examinados em maior detalhe, considerando a complexidade das relações de agência existentes.

Concluímos também que as ideias teóricas de conflitos entre principais e agentes, entre principais majoritários e minoritários, entre principal e credor podem vir a ser novas formas de se entender as organizações por meio dos estudos das práticas. Além de que, tanto criar mecanismos de monitoramento quanto mecanismos de incentivo baseados em resultados, são formas de amenizar os conflitos de agência. Como resultado, a Teoria da Agência pode ser ajustada ou adaptada para fornecer uma compreensão mais rica da dicotomia principal-agente e possíveis maneiras pelas quais seus relacionamentos podem ser alterados para resultar em organizações mais eficientes. 


\section{Referências}

ARROW, K. Essays in the theory of risk bearing. Chicago: Markham. 1971. Disponível em $<$ https://www.academia.edu/30504924/Reviews_of_Essays_in_the_Theory_of_Risk_Bearing _by_Kenneth_J._Arrow.pdf>. Acesso em: 28 maio 2019.

BENDICKSON, Josh; et al. Agency theory: the times, they are a-changin'. In: Management Decision. Vol. (54), nr 1, p. 174-193. 2016.

BERLE, A.; MEANS, G. The modern corporation and private property. New York, NY: Macmillan, 1932. Disponível em <https://learn.canvas.net/courses/1446/files/549357>. Acesso em: 28 maio 2019.

DAMODARAN, A. Corporate finance. New York: John Wiley, 1997.

EISENHARDT, K. M. Agency theory: an assessment and review. In: Academy of Management Review. Vol. (14), nr 1, p. 57-74. 1989.

FAMA, E. Agency problems and the theory of the firm. In: Journal of Political Economy, Vol. (88), nr 2, p. 288-307. 1980.

IYER, Pico. China: capitalism in the making. In: Time. Apr. 30, 1984. Disponível em $<$ http://content.time.com/time/magazine/article/0,9171,951047,00.html $>$. Acesso em: 31 maio 2019.

JENSEN, M. Agency cost of free cash flow, corporate finance, and takeovers. In: American Economic Review. Vol. (76), nr 2, p. 323-329; 1986.

JENSEN, M.; MECKLING, W. Theory of the firm: Managerial behavior, agency costs, and ownership structure. In: Journal of Financial Economics. Vol. (3), nr 4, p. 305-360; 1976.

JONES, Gareth R.; BUTLER, John E. Managing internal corporate entrepreneurship: an agency theory perspective. In: Journal of Management. Vol. (18), nr 4, p. 733 - 749. 1992.

LINDER, S.; FOSS, N. J. Agency Theory. In: International Encyclopedia of the Social \& Behavioral Sciences. 2nd edition, Volume 1. 2015.

MAPA, Ministério da Agricultura, Pecuária e Abastecimento. A cachaça no Brasil: dados de registro de cachaças e aguardentes. Brasília: MAPA, 2019.

MASON, Daniel S.; SLACK, Trevor. Agency Theory and the study of sport organizations. In: Sport in Society. Vol. (8), nr 1, p. 48-64. 2005.

MASON, Daniel S.; SLACK, Trevor. Evaluating Monitoring Mechanisms as a Solution to Opportunism by Professional Hockey Agents. In: Journal of Sport Management. Vol. (15), nr 2, p. 107-34. 2001.

MITNICK, B. The theory of agency: the policing 'paradox' and regulatory behavior. In: Public Choice. Vol. (24), nr 1, p. 27-42. 1975.

PANDA, Brahmadev; LEEPSA, N. M. Agency theory: review of theory and evidence on problems and perspectives. In: Indian Journal of Corporate Governance. Vol. (10), $\mathrm{nr}$ 1, p. 74-95; 2017. 
RASHID, Afzalur. Revisiting Agency Theory: evidence of borard independence and agency cost from Bangladesh. In: Journal of Business Ethics, nr 130, p. 181-198. 2015.

ROSS, S. The economic theory of agency: the principal's problem. In: American Economic Review. Vol. (63), nr 2, p. 134-139. 1973.

SMITH, Adam. A riqueza das nações. Volume I. São Paulo: Nova Cultural, 1996.

WILSON, R. On the theory of syndicates. In: Econometrica. Vol. (36), nr 1, p. 119 132. 1968.

WISEMAN, R. M.; RODRÍGUEZ, G. C.; MEJIA, L. R. G. Towards a social Theory of Agency. In: Journal of Management Studies. Vol. (49), nr 1. 2012.

WRIGHT, P.; MUKHERJI, A.; KROLL, M. J. A reexamination of agency theory assumptions: extensions and extrapolations. In: The Journal of Socio-Economics, $\mathrm{nr}$ 30, p. 413-429. 2001. 